\title{
Tobacco mosaic virus Induced Alterations in the Gene Expression Profile of Arabidopsis thaliana
}

\author{
Sheetal Golem ${ }^{1}$ and James N. Culver ${ }^{1,2}$ \\ ${ }^{1}$ Molecular and Cell Biology Program, University of Maryland; ${ }^{2}$ Center for Biosystems Research, University of Maryland \\ Biotechnology Institute, College Park, MD 20742, U.S.A.
}

Submitted 24 January 2003. Accepted 15 April 2003.

In this study, mRNA profiles generated from cDNA microarrays were used to identify gene expression changes in Arabidopsis thaliana ecotype Shahdara infected with Tobacco mosaic virus (TMV). Shahdara is a susceptible TMV host, permitting rapid accumulations of virus in both inoculated and systemic tissues, accompanied by defined disease symptoms that include stunting, necrosis, and leaf curling. Gene expression profiles were monitored in whole tissues of inoculated leaves at four days postinoculation (dpi) and in systemically infected leaves at $14 \mathrm{dpi}$. Microarrays contained cDNAs representing between 8,000 and 10,000 Arabidopsis genes. Expression analysis identified 68 genes that displayed significant and consistent changes in expression levels, either up or down, in either TMV inoculated or systemically infected tissues, or both. Identified TMV-responsive genes encode a diverse array of functional proteins that include transcription factors, antioxidants, metabolic enzymes, and transporters. Thus, the TMV infection process has a significant impact on a wide array of cellular processes that likely reflect the biochemical and physiological changes involved in the development of this disease syndrome.

Additional keywords: virus-host interactions, transcriptome.

Virus infections typically disrupt a host's normal physiology. This disruption reflects a combination of processes that include the diversion of metabolites for the production of virus-specific components, alterations that either enhance virus replication, suppress host defense mechanisms, or both, and cellular responses that compensate for the effects of viral-induced changes (Matthews 1991). Cumulatively, these processes and the changes they induce determine the level and type of disease response displayed by the host. In plants, virus-induced diseases can vary widely in severity, ranging from tolerant responses that convey little effect on host physiology to severe responses that result in plant death. Unfortunately, our knowledge of the viral and cellular processes responsible for such divergent disease responses is limited. However, underlying many of these different disease responses are changes in host gene expression. Therefore, identifying host genes that display virus-induced alterations in their expression patterns can provide a means to link specific viral and cellular processes to the development of a disease response.

To date, only a few plant genes have been shown to be differentially regulated in the presence of an infecting virus.

Corresponding author: James N. Culver: Telephone: (301) 405-2912; Fax: (301) 314-9075; E-mail: jc216@umail.umd.edu.
Many of these genes show transient variations in expression levels that correspond with the advancing virus infection front. Within this group are genes such as lipoxygenase 1 and heat shock cognate protein that show repression only within pea cells displaying active Pea seed-borne mosaic virus (PSbMV) replication (Aranda and Maule 1998; Aranda et al. 1996; Wang and Maule 1995). Conversely, genes such as heat shock protein 70 or polyubiquitin were shown to display marked increases in expression within cells supporting a range of different viruses (Escaler et al. 2000). Still other genes, such as catalase and NADP-dependent glyceraldehyde-3-phosphate dehydrogenase, display more stable expression shifts in response to Cucumber mosaic virus infection, even in the uninfected tissues located ahead of the advancing infection front (Havelda and Maule 2000). From these findings, it is apparent that virus infections have a complex and variable effect on host gene expression.

Previously, the identification and characterization of genes regulated in response to specific treatments has been done individually or in small groups. In contrast, microarray technology permits the simultaneous analysis of large numbers of genes in response to specific conditions. Within plants, microarrays have been used to investigate transcriptional changes that occur in response to a number of treatments, including responses to nutritional deficiencies, circadian rhythms, and pathogen attack (Chen et al. 2002; Schaffer et al. 2001; Thimm et al. 2001). For plant viruses, both macro- and microarray studies investigating virus- and viroid-host interactions have recently been reported (Itaya et al. 2002; Whitham et al. 2003). These studies mark initial efforts to understand virus-host interactions at the genomic level. To further expand this understanding, this study investigated the gene expression profiles of Arabidopsis thaliana ecotype Shahdara infected with Tobacco mosaic virus (TMV) for both inoculated and systemically infected leaf tissues. TMV is the type member of the genus Tobamovirus and a member of the "alphavirus supergroup". Its genome, consisting of a single-strand of positive sense RNA, encodes at least four proteins (Goelet et al. 1982). Two proteins, a 126-kDa protein and a readthrough 183-kDa protein are involved in virus replication (Ishikawa et al. 1986; Pelham 1978). The remaining proteins include a $30-\mathrm{kDa}$ protein required for cell-to-cell movement and a $17.5-\mathrm{kDa}$ capsid protein (Deom et al. 1987; Hunter et al. 1976; Meshi et al. 1987). Arabidopsis ecotype Shahdara permits the rapid accumulation of TMV in both inoculated and systemic tissues (Dardick et al. 2000). The timing and appearance of this susceptible response is similar to that observed in other TMV hosts, such as pepper, tobacco, and tomato. Thus, the TMV-Shahdara system is ideal for investigating the molecular effects of virus-induced disease development. 
To examine changes in the transcriptome of Shahdara infected with TMV, we utilized cDNA microarrays created by the Arabidopsis Functional Genomics Consortium (AFGC). These arrays contain cDNAs representing approximately one quarter of all known or predicted Arabidopsis genes. Results identified a set of genes whose expression patterns show significant alterations in either TMV inoculated, systemically infected whole leaf tissues, or both. The functional identity of these genes and their putative role in the disease process are discussed.

\section{RESULTS}

\section{Construction}

of expression data sets and sources of variability.

Gene expression levels in Shahdara were monitored in inoculated leaves at 4 days postinoculation (dpi) and in systemically infected leaves at $14 \mathrm{dpi}$. These timepoints were selected for analysis based on previous results demonstrating significant accumulations of TMV in either the inoculated or systemic tissues at these times (Dardick et al. 2000). Additionally, TMV-induced symptoms, including stunting and leaf curling, first appear at $14 \mathrm{dpi}$ in the systemically infected tissues (Fig. 1).

Three independent biological replicates were used to monitor gene expression at both 4 and 14 dpi (Table 1). For each biological replicate, leaf tissue from at least 25 infected or mock-inoculated plants was pooled for mRNA isolations. To control for environmental and circadian effects, all plants were maintained under identical conditions with both inoculations and RNA extractions done at the same time of day. To account for inconsistencies in probe labeling and detection, each mRNA pool was used to generate two reciprocally labeled sets of cDNA probes (Cy3-mock/Cy5-infected or Cy3-infected/Cy5-mock). Each probe set was hybridized to a cDNA microarray spotted with Arabidopsis expressed sequence tags (ESTs) representing approximately 8,000 (replicate 1) or 10,000 genes (replicates 2 and 3) ( Table 1). Signal intensities from individual array spots were normalized and used to calculate the log-transformed $\mathrm{Cy} 5$ to $\mathrm{Cy} 3$ ratio, representing the relative change in the amount of an mRNA between mock and infected samples. Genes represented by array spots that displayed changes in this ratio above a cutoff of \pm 1.95 standard deviation from the mean of all array spots fell outside the $95 \%$ confidence interval (CI) and were considered to be regulated in response to TMV infection (Fig. 2) (Gill et al. 2002a, 2002b)

To identify genes that displayed consistent expression changes in response to TMV, the data sets from each biological replicate were compiled and averaged for individual genes. The $95 \%$ CI for all three data sets was determined and used as a cutoff to create a final data set containing only those genes that consistently showed alterations in expression levels during TMV infection (Table 2). Variation that interfered with the analysis of data between the three biological replicates primarily resulted from either missing or excluded data. Missing data occurred when a gene present on the larger, approximately 10,000 gene array slides used in replicates 2 and 3 was not present on the smaller, approximately 8,000 gene slides used in replicate 1 (Table 1). Data exclusion occurred when individual microarray spots produced weak or uneven hybridization signals, making the data

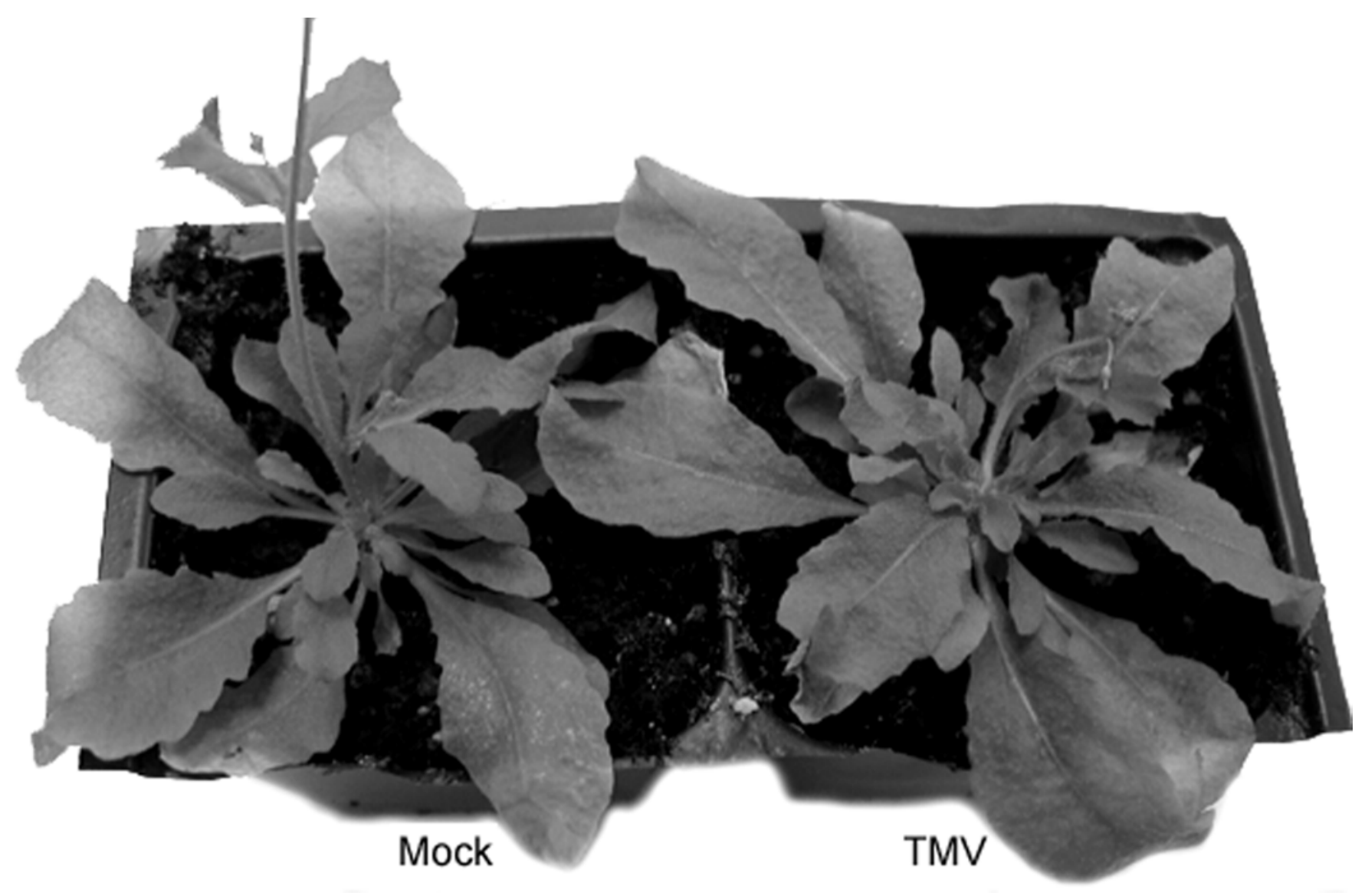

Fig. 1. Tobacco mosaic virus (TMV) symptom expression in Shahdara. Mock-inoculated and TMV-infected plants at 14 days postinoculation. Mature inoculated rosette leaves and systemically infected rosette and cauline leaves were used in array analysis. 
unusable in at least one of the biological replicates. Data spots having missing or excluded data in two or more replicates were not utilized in our analysis.

\section{Identification and classification \\ of TMV-responsive Arabidopsis genes.}

Data sets from each biological replicate were compiled to identify genes that displayed significant changes in expression levels. Comparisons using a 95\% CI cutoff identified 23 genes as altered in their expression at $4 \mathrm{dpi}$ in inoculated leaf tissues and 53 genes altered at 14 dpi in systemically infected leaf tissues. Within this final data set, missing or excluded data resulted in six of the 23 genes from the inoculated replicates and 25 of 53 genes from the systemic replicates being selected, using data from only two biological replicates. The remainder of the genes in the final data set were selected based on data averaged from all three biological replicates. All 23 of the genes altered in the inoculated tissue showed induced levels of transcription. In the systemic tissue, 18 of the 53 regulated genes were induced, whereas 35 were repressed.

Identified TMV-responsive genes were classified into eight functional categories based on their predicted functions (Table 2). Unclassified genes that contained no significant homologies to known proteins made up the largest group of TMV-responsive genes at both 4 and 14 dpi. Within the inoculated leaves at $4 \mathrm{dpi}$, the remainder of the identified genes were relatively equally dispersed among signal transduction, transcription, stress, metabolism, and transport functions. However, within systemically infected tissues a noticeably higher proportion of TMV-responsive genes were classified as transcription factors, stress-related proteins, and metabolic enzymes. Taken together, these data indicated that TMV infection induces varied effects on the expression profiles of a functionally diverse set of genes.

Comparison of the array data generated at 4 and 14 dpi revealed that the majority of the identified TMV-responsive genes maintain a similar expression trend in both the inoculated and systemic tissues (Fig. 3). However, only eight genes displayed expression levels outside the $95 \%$ CI cutoff at both timepoints. Six of these genes, a superoxide dismutase, Akinbeta 1 , a seed imbibition protein, and three unclassified proteins, displayed significantly higher levels of expression in the systemically infected tissues than in the inoculated tissue. Two genes, conglutin gamma and AtHVA22c, displayed the same level of expression at both timepoints.

\section{Expression profiles of TMV-responsive genes in other stress related treatments.}

The expression levels of all $68 \mathrm{TMV}$-responsive genes were examined in other Arabidopsis stress response data sets posted on the Stanford microarray database. These experimental data sets were derived from 34 independent array slides involving treatments that included: the application of antimycin A, hydrogen peroxide, and vomitoxin; nutrient deficiencies in potassium, iron, and sulfate, as well as nickel hyperaccumulation; infections by Pseudomonas syringae and virus treatments examining tolerance to Tobacco ring spot virus, suppression of the hypersensitive response by Turnip crinkle virus, and the transgenic expression of Cauliflower mosaic virus gene VI. Within all treatments, no general stress response genes were found, i.e., no one gene or combination of genes showed the same expression pattern in all treatments. Furthermore, none of the TMV-responsive genes were regulated in a specific manner only in response to TMV infection.

\section{DISCUSSION}

Viruses can alter the transcriptional networks of their hosts. These alterations represent both the direct and indirect effects of virus replication and the development of disease. Thus, understanding virus-induced changes in host gene expression provides a valuable means of identifying the host processes involved in virus biology. Within this study, cDNA microarrays were used to investigate the effects of TMV infection on the transcriptome of the susceptible Arabidopsis ecotype Shahdara. This technology allowed the simultaneous screening of approximately 8,000 to 10,000 Arabidopsis genes for their response to TMV infection. Genes identified as TMV responsive likely represent affected host processes and provide candidate genes for further investigation of the interactions of viruses with their hosts.

Data analysis using three independent biological replicates proved to be important for overcoming variations derived from both technical and biological sources. Technical variations, resulting from genes missing on the smaller array or low quality hybridization signals, combined to prevent the analysis of only a small number of genes in one or more of the biological replicates. Biological variation affected a larger number of genes. This variation is revealed by the total number of genes, 124 in the inoculated replicates and 320 in the systemic replicates, that displayed TMV-induced expression changes outside the 95\% CI cutoff in any one of the three biological replicates. For the majority of these genes, 92 in the inoculated replicates and

Table 1. Microarray information

\begin{tabular}{|c|c|c|c|c|c|c|}
\hline \multirow[b]{2}{*}{ Replicate $^{\mathbf{a}}$} & \multirow[b]{2}{*}{ Dpi ${ }^{b}$} & \multirow[b]{2}{*}{ Slide name } & \multicolumn{2}{|c|}{ Labeling } & \multicolumn{2}{|c|}{ Number of genes } \\
\hline & & & Cy3 & Cy5 & Altered $^{c}$ & Tested $^{\text {d }}$ \\
\hline \multirow[t]{2}{*}{ Biological Replicate 1} & $4 \mathrm{dpi}$ & $\mathrm{J} 27$ & Mock & TMV & 23 & 8,000 \\
\hline & & J28 & TMV & Mock & & \\
\hline \multirow[t]{2}{*}{ Biological Replicate 2} & $4 \mathrm{dpi}$ & K131 & Mock & TMV & 87 & 10,000 \\
\hline & & K138 & TMV & Mock & & \\
\hline \multirow[t]{2}{*}{ Biological Replicate 3} & 4 dpi & K152 & Mock & TMV & 45 & 10,000 \\
\hline & & K153 & TMV & Mock & & \\
\hline \multirow[t]{2}{*}{ Biological Replicate 1} & 14 dpi & $\mathrm{J} 31$ & Mock & TMV & 113 & 8,000 \\
\hline & & $\mathrm{J} 32$ & TMV & Mock & & \\
\hline \multirow[t]{2}{*}{ Biological Replicate 2} & 14 dpi & K160 & Mock & TMV & 141 & 10,000 \\
\hline & & K164 & TMV & Mock & & \\
\hline \multirow[t]{2}{*}{ Biological Replicate 3} & $14 \mathrm{dpi}$ & K154 & Mock & TMV & 133 & 10,000 \\
\hline & & K155 & TMV & Mock & & \\
\hline
\end{tabular}


206 in the systemic replicates, expression values within the two replicates having values below the cutoff maintained the same expression trend, either repressed or induced, only at a reduced level. The possibility exists that these genes are regulated in response to TMV but at a level that averages to below the cutoff used in these experiments. Therefore, establishment of expression cutoffs, such as the $95 \%$ CI used in this study,

\section{Inoculated Tissue}
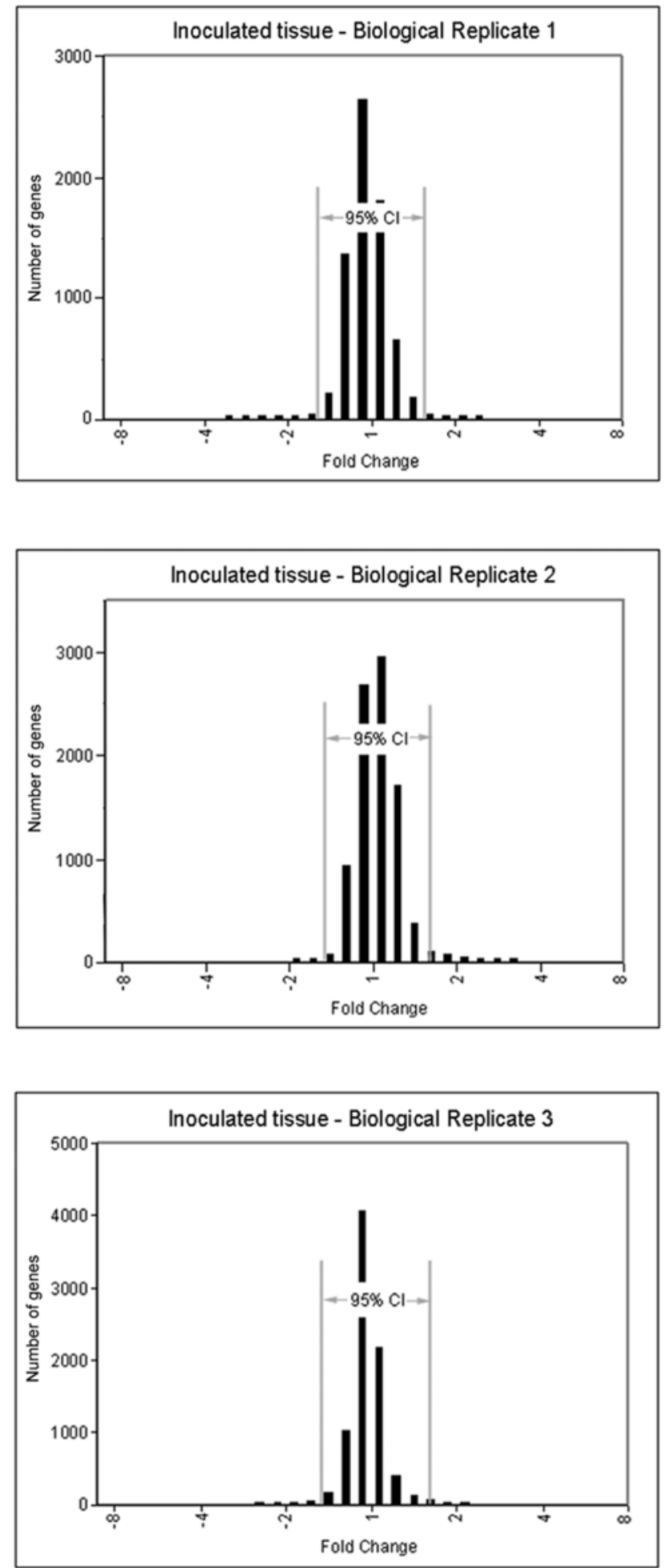

may limit the detection of subtle expression changes. The remainder of the genes, 32 in the inoculated replicates and 114 in the systemic replicates, displayed no expression similarities in the two replicates with values below the cutoff. This biological "noise" appeared even though each replicate represented RNA pooled from at least 25 individual plants that were maintained under identical conditions.
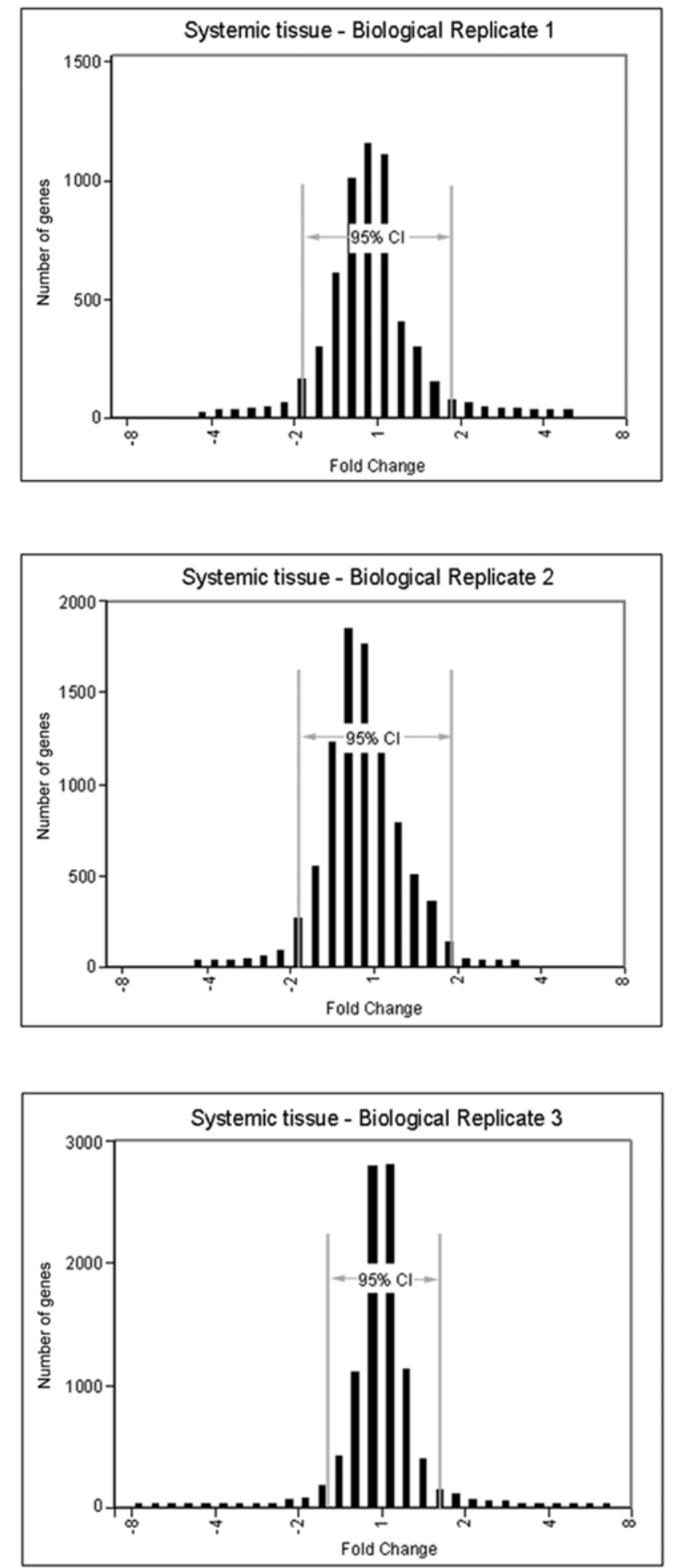

Fig. 2. Data profiles for individual biological replicates from inoculated and systemic tissues. Genes having a fold expression change outside the marked 95\% confidence interval were considered regulated in response to TMV infection. 
In this study, only 68 Arabidopsis genes showed consistent expression changes in response to TMV infection. This suggests that, at the whole tissue level, TMV infection does not dramatically affect the Arabidopsis transcriptome. This finding is consistent with a previous study that found TMV infection did not alter the overall mRNA content in tobacco leaves (Fraser and Gerwitz 1980). Additionally, recent array studies have found a similarly low percentage of genes altered in response to virus infection (Itaya et al. 2002; Whitham et al. 2003). Comparisons with the gene expression profiles of other virusinduced arrays, including TMV in tomato and related Tobamoviruses in Arabidopsis, reveal a number of similarities in the types of genes that display expression changes in response to virus infection (Itaya et al. 2002; Whitham et al. 2003). The most significant similarities occurred for stress-related genes, such as thioredoxin, glutathione-S-transferase and $\beta$-glucanse, and for transcriptional elements, such as the WRKY DNA binding protein and an ethylene-responsive binding factor. Further comparisons of the gene expression profiles of TMV- responsive genes in 12 other stress-related treatments deposited on the Stanford microarray database demonstrated that none of these genes were altered in expression only in response to TMV infection. Together, these findings suggest that TMVinduced expression changes are relatively limited in whole leaf tissues and consistent with responses observed in other stress treatments and virus infections.

At 4 dpi, all of the identified TMV-responsive genes were induced in transcription. In contrast, 35 of the 53 genes regulated at 14 dpi showed repression. This increase in the number of repressed genes at 14 dpi may reflect the general repression of host genes observed in other systems during active virus replication. For example, shutoff of host transcription has been observed for a diverse group of RNA viruses that include Poliovirus and PSbMV (Yalamanchili et al. 1996; Wang and Maule 1995). This form of general repression may be more evident in systemic tissues in which virus movement and accumulation occurs more rapidly (Matthews 1991; Samuel 1934). Alternatively, the increase in the number of genes identified at

Table 2. Genes of Arabidopsis ecotype Shahdara altered in TMV- inoculated (4 dpi) and systemically infected tissues (14 dpi)

\begin{tabular}{|c|c|c|c|c|c|}
\hline $\begin{array}{l}\text { AFGC gene } \\
\text { model ID }\end{array}$ & $\begin{array}{c}\text { Functional category/ } \\
\text { protein name }^{\mathbf{b}}\end{array}$ & $\begin{array}{c}\text { Fold } \\
\text { expression }^{\mathrm{c}}\end{array}$ & $\begin{array}{l}\text { AFGC gene } \\
\text { model ID }^{\mathbf{a}}\end{array}$ & $\begin{array}{c}\text { Functional category/ } \\
\text { protein name }^{\mathbf{b}}\end{array}$ & $\begin{array}{c}\text { Fold } \\
\text { expression }^{\mathrm{c}}\end{array}$ \\
\hline $4 \mathrm{dpi}$ & Unclassified & & $14 \mathrm{dpi}$ & Unclassified & \\
\hline At1g69700 & AtHVA22 $c^{d}$ & 1.9 & At1g03600 & Unknown protein & -2.1 \\
\hline At $2 \mathrm{~g} 41430$ & Unknown protein & 1.9 & At3g17790 & Acid phosphatase type 5 & -2.3 \\
\hline At3g61060 & Unknown protein & 1.9 & At1g69490 & Unknown protein & -2.6 \\
\hline At $2 \mathrm{~g} 24550$ & Unknown protein & 1.9 & At2g25950 & Unknown protein & -2.7 \\
\hline At $\lg 57980$ & Unknown protein & 1.8 & & Transcription & \\
\hline At1g57990 & Unknown protein ${ }^{\mathrm{d}}$ & 1.8 & At5g22580 & Unknown protein & -3.3 \\
\hline At1g80440 & Unknown protein & 1.7 & At $2 \mathrm{~g} 16520$ & Hypothetical protein & -3.8 \\
\hline At4g32480 & Putative protein $^{\mathrm{d}}$ & 1.7 & At5g19120 & Conglutin gamma like protein ${ }^{\mathrm{d}}$ & 2.1 \\
\hline At5g14120 & Nodulin-like protein & 1.7 & At $2 \mathrm{~g} 22430$ & Homeodomain transcription factor & -1.9 \\
\hline At $\lg 22890$ & Unknown protein & 1.7 & At5g65640 & Putative bHLH transcription factor & -2.1 \\
\hline At5g20250 & Seed-imbibition protein ${ }^{\mathrm{d}}$ & 1.7 & At5g46250 & Putative transcription factor & -2.1 \\
\hline \multirow{2}{*}{ At2g44130 } & Unknown protein & 1.6 & At3g60300 & Putative transcription factor & -2.2 \\
\hline & Transcription & & At3g24500 & Ethylene responsive transcriptional coactivator & -2.5 \\
\hline At5g19120 & Conglutin gamma like protein ${ }^{\mathrm{d}}$ & 2.1 & At3g16770 & AP2 domain containing protein RAP2.3 & -4.6 \\
\hline \multirow[t]{2}{*}{ At5g61600 } & DNA binding protein & 1.5 & & Signal transduction & \\
\hline & Signal Transduction & & At5g21170 & AKIN beta $1^{\mathrm{d}}$ & 3.0 \\
\hline \multirow[t]{2}{*}{ At5g21170 } & AKIN beta ${ }^{\mathrm{d}}$ & 1.9 & At3g23000 & SNF1 related protein kinase & -2.3 \\
\hline & Metabolism & & & Metabolism & \\
\hline At2g18700 & Trehalose-6-phosphate synthase & 1.8 & At5g49360 & Xylosidase & 2.3 \\
\hline At5g57530 & Xyloglucan endotransglycosylase & 1.7 & At3g55430 & Beta-1,3-glucanase like protein & 1.9 \\
\hline \multirow[t]{2}{*}{ At3g50740 } & UTP-glucose glucosyltransferase & 1.6 & At2g41290 & Putative strictosidine synthase & -1.9 \\
\hline & Transport & & At5g53970 & Tyrosine aminotransferase & -2.0 \\
\hline At1g11260 & Glucose transporter & 1.9 & At1g65960 & Putative glutamate decarboxylase & -2.0 \\
\hline \multirow[t]{2}{*}{ At $2 \mathrm{~g} 28900$} & Membrane channel protein & 1.6 & At1g56600 & Galactinol synthase & -2.0 \\
\hline & Stress & & At4g13840 & Fatty acid elongase like protein & -2.1 \\
\hline At3g01290 & Putative stress related protein ${ }^{\mathrm{d}}$ & 1.8 & At5g01670 & Aldose reductase like protein & -0.2 \\
\hline At1g08830 & Copper zinc superoxide dismutase ${ }^{\mathrm{d}}$ & 1.7 & At3g 12120 & Putative fatty acid desaturase & -2.3 \\
\hline \multirow[t]{2}{*}{ At1g80920 } & Putative J8-like protein & 1.7 & At3g14210 & Myrosinase associated protein & -3.9 \\
\hline & & & & Transport & \\
\hline $14 \mathrm{dpi}$ & Unclassified & & At1g48750 & Putative lipid transfer protein & 2.7 \\
\hline At4g32480 & Putative protein $^{\mathrm{d}}$ & 2.9 & At4g17340 & Membrane channel like protein & -2.3 \\
\hline At2g17230 & Unknown protein & 2.5 & & Stress & \\
\hline At5g20250 & Seed-imbibition protein ${ }^{\mathrm{d}}$ & 2.5 & At5g67480 & Putative stress related protein & 3.1 \\
\hline At1g57990 & Putative protein ${ }^{\mathrm{d}}$ & 2.0 & At3g01290 & Putative stress related protein ${ }^{\mathrm{d}}$ & 2.9 \\
\hline At1g69700 & AtHVA22 $c^{d}$ & 1.9 & At3g03790 & Putative stress related protein & 2.6 \\
\hline At1g70090 & Unknown protein & 1.8 & At1g08830 & Copper zinc superoxide dismutase ${ }^{\mathrm{d}}$ & 2.2 \\
\hline At2g14910 & Unknown protein & -1.9 & At1g24020 & Pollen allergen like protein & 2.1 \\
\hline At1g70890 & Major latex protein & -1.9 & At2g28190 & Putative copper zinc superoxide dismutase & 2.0 \\
\hline At5g02160 & Putative protein & -1.9 & At5g43460 & Nicotiana-lesion inducing protein & 1.9 \\
\hline At1g19350 & Unknown protein & -2.0 & At5g21010 & Putative stress related protein & -3.5 \\
\hline At1g73390 & Hypothetical protein & -2.0 & At5g46700 & Senescence-associated protein & -4.6 \\
\hline At $4 \mathrm{~g} 10060$ & Putative protein & -2.1 & & DNA repair & \\
\hline At5g38980 & Putative protein & -2.1 & At5g41360 & DNA excision repair protein & -2.1 \\
\hline At3g17710 & Unknown protein & -2.1 & & Cellular biogenesis & \\
\hline At2g46940 & Unknown protein & -2.1 & At4g37990 & Cinnamyl alcohol dehydrogenase & -2.1 \\
\hline
\end{tabular}

${ }^{\text {a AFGC }}=$ Stanford University's Arabidopsis Functional Genomics Consortium.

${ }^{\mathrm{b}}$ Average of channel intensity ratios (CH2N/CH1) from all the biological replicates.

${ }^{\mathrm{c}}$ Genes altered in both inoculated and systemic tissues.

${ }^{\mathrm{d}}$ Gene functions were assigned based on information from sequence homologies and the MIPS Arabidopsis thaliana database. 
14 dpi may reflect specific responses to the presence of the virus in newly developing tissues. This possibility is supported by the disproportionate increase in the number of altered genes within the systemically infected tissues that were functionally classified as either transcription factors, stress related proteins, or involved in metabolism (Table 2). Thus, a TMV infection within systemic tissues may selectively impact genes within these three functional categories. Furthermore, the greater number of genes affected at the systemic level may reflect changes that contribute to the development of symptoms such as stunting and leaf curling that are observed only in systemically infected tissues.

Expression changes for TMV-responsive genes above the $95 \%$ CI cutoff ranged between 1.5- to 2.1-fold induction in inoculated leaves and between -4.6-fold repression to 3.1-fold induction in systemic tissue (Table 2). The greater fold changes in expression within systemically infected leaves may reflect the higher levels of TMV infection present within systemically infected Shahdara leaves than is found in inoculated tissues at 4 dpi (Dardick et al. 2000). Of the 68 identified TMV-responsive genes, only eight shared changes in expression levels outside the 95\% CI cutoff in both the inoculated and systemic tissues. These eight all showed induced levels of transcription in the presence of TMV at both sample times. An additional 47 of the remaining 60 genes displayed similar expression trends in both tissues, suggesting that gene expression profiles at 4 and 14 dpi are more similar than indicated by the $95 \%$ CI cutoff (Fig. 3). The 13 remaining genes displayed opposite expression trends between the inoculated and systemic tissues (Fig. 3). Thus, the tissue-specific regulation of host genes in response to TMV infection can occur at the whole tissue level. The predicted functions of all the TMV-responsive genes include transcription, metabolism, signal transduction, and stress, indicating that TMV affects a range of host functions at the plant-wide level.

The data presented in this study demonstrates the varied effects of TMV infection on a susceptible host. The identified genes likely reflect stable TMV-induced alterations within the gene expression profile of whole tissues. These responses may be either directly or indirectly responsible for the disease responses observed in ecotype Shahdara. Additionally, it is clear from previous studies in both plants and animals that viruses can also transiently affect host gene transcription (Wang and Maule 1995). Transient changes would likely be displayed only in cells containing actively replicating virus. It is likely that both stable and transient expression changes contribute to the display of disease symptoms. Thus, transcription profiles in both whole tissues as well as in cells containing actively replicating virus are needed to develop a full understanding of the effects of virus replication on host physiology.

\section{MATERIALS AND METHODS}

\section{Plant growth conditions and inoculations.}

Shahdara plants were grown and maintained in growth chambers under a 12 -h photoperiod at $23^{\circ} \mathrm{C}$ and $50 \%$ relative humidity. Four-week-old plants were used for virus inoculations. Mature rosette leaves of the plants were dusted with Carborundum (Fisher Scientific Company, Pittsburgh, PA, U.S.A.) and were mechanically inoculated with $10 \mu \mathrm{g}$ of purified TMV. Control plants were similarly dusted with Carborundum and
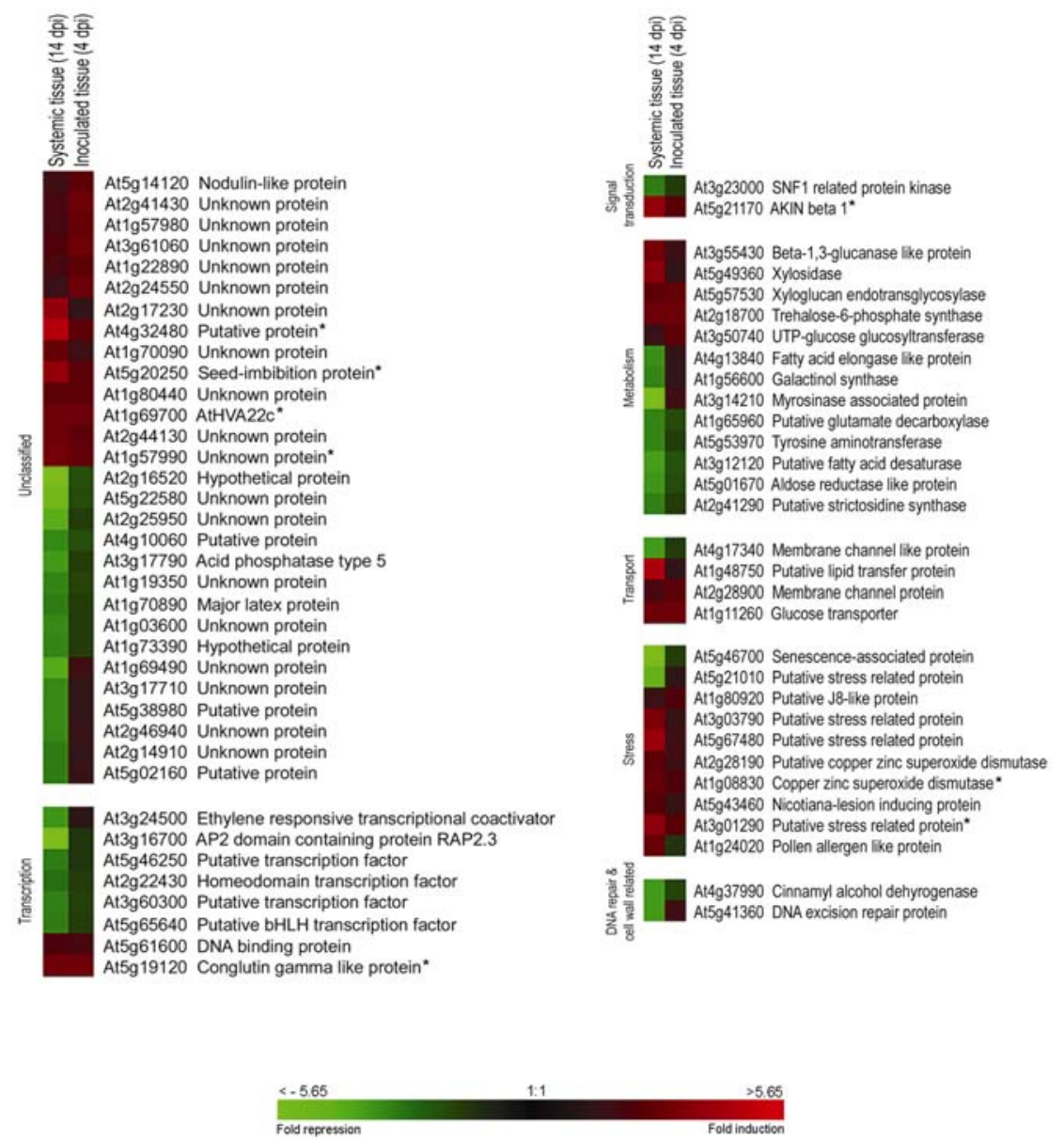

Fig. 3. Expression trends of Tobacco mosaic virus (TMV) responsive genes at 4 days postinoculation (dpi) the inoculated leaf tissue and 14 dpi in the systemic leaf tissue. Genes having expression changes above the $95 \%$ confidence interval at both sample times are marked with an asterisk. 
mock-inoculated with distilled water. Inoculated rosette leaves were harvested at $4 \mathrm{dpi}$ and systemically infected rosette and cauline leaves, which developed after inoculation, were harvested at $14 \mathrm{dpi}$. For consistency between biological replicates, virus inoculations and tissue harvesting for mRNA extractions were done at same time of day.

\section{Extraction of total and poly A RNA.}

Total RNA was extracted from inoculated rosette leaves of mock- and TMV-inoculated Shahdara plants at 4 dpi and from the uninoculated rosette and cauline leaves at 14 dpi, using Trizol reagent (Chomczynski and Sacchi 1987) (Invitrogen Life Technologies, Carlsbad, CA, U.S.A.). In summary, harvested plant tissue was ground in liquid nitrogen and treated with Trizol reagent, $15 \mathrm{ml}$ per gram of tissue, followed by centrifugation at $12,000 \times \mathrm{g}$. The supernatant was treated with $3 \mathrm{ml}$ of chloroform and was centrifuged at $10,000 \times \mathrm{g}$ for $15 \mathrm{~min}$. The RNA was precipitated by the addition of isopropanol in the presence of $1.2 \mathrm{M}$ sodium citrate and $0.8 \mathrm{M}$ sodium chloride. The RNA pellet obtained was resuspended in $250 \mu \mathrm{l}$ of diethylpyrocarbonate water containing RNAse inhibitor (Promega, Madison, WI, U.S.A.). Poly A(+) RNA was isolated from the total RNA samples using the Oligotex mRNA isolation system (Qiagen, Valencia, CA, U.S.A.).

\section{Microarray fabrication and sample processing.}

Microarray slides were manufactured by the AFGC at Michigan State University (Lansing, MI, U.S.A.). About 15,000 ESTs representing a quarter of the Arabidopsis genome were robotically spotted onto glass slides (Newman et al. 1994; Schaffer et al. 2001) (Telechem International, Sunnyvale, CA, U.S.A.). Messenger RNA samples were reverse transcribed in the presence of fluorescent $\mathrm{Cy} 3$ - and Cy5-labeled nucleotides to obtain labeled cDNA that was hybridized to the microarray slides. Three biological replicates were used for each timepoint. The mRNA from each biological replicate was labeled with either Cy3-mock/ Cy5-infected or Cy3-infected/ Cy5mock, and each labeled set was hybridized against a single array slide. The hybridization signal for each channel (Cy3 and Cy5) was read using an Affymetrix 428 microarray scanner (Affymetrix, Inc., Santa Clara, CA, U.S.A.). Hybridization data was analyzed using the gridding softwares, ScanAlyze or Genepix (Axon Instruments, Inc., Union City, CA, U.S.A.), and the raw data was deposited in the Stanford microarray database (Sherlock et al. 2001).

\section{Data analysis.}

EST spots that were not flagged and those that had a regression correlation of greater than 0.6 were selected for further analysis (Schuchhardt et al. 2000; Sherlock 2000). The average natural logarithm for ratio of channel intensities (Cy5/Cy3) was calculated for the selected spots. This value was raised to power ' $\mathrm{e}$ ' to get a normalization value, $\mathrm{N}$. The data in channel 2 (Cy5) was divided by ' $\mathrm{N}$ ' to obtain normalized values for channel 2 intensities. These normalized values were used to calculate the ratio of channel intensities (Cy5N/Cy3), which were then log transformed. The average $(\mu)$ and standard deviation $(\sigma)$ were calculated for the log-transformed ratios. The 95\% CI $(\mu \pm 1.95 \sigma)$ was calculated and was used to identify EST spots that displayed significant changes in signal intensities.

\section{ACKNOWLEDGMENTS}

We thank V. Simon and E. Wisman as well as other members of the Arabidopsis Functional Genomics Consortium for assistance in setting up and conducting array experiments; L. Mcintosh, S. Neill, M. Guerinot, J. Schroeder, S. He, L. Domier, R. Ingle, A. Smith, J. Schoelz, K. Wobbe, A.
Bones, P. Hart, Z. Wang, K. Ramonell, and others for making their array data publicly available via the Stanford microarray database, and $\mathrm{H}$. Shiferaw and M. Padmanabhan for critically reading the manuscript. This work was supported in part by grant No. IBN-0113536 from the National Science Foundation.

\section{LITERATURE CITED}

Aranda, M. A., Escaler, M., Wang, D., and Maule, A. J. 1996. Induction of HSP70 and polyubiquitin expression associated with plant virus replication. Proc. Natl. Acad. Sci. U.S.A. 93:15289-15293.

Aranda, M. A., and Maule, A. J. 1998. Virus-induced host gene shutoff in animals and plants. Virology 243:261-267.

Chen, W., Provart, N. J., Glazebrook, J., Katagiri, F., Chang, H. S., Eulgem, T., Mauch, F., Luan, S., Zou, G., Whitham, S. A., Budworth, P. R., Tao, Y., Xie, Z., Chen, X., Lam, S., Kreps, J. A., Harper, J. F., SiAmmour, A., Mauch-Mani, B., Heinlein, M., Kobayashi, K., Hohn, T., Dangl, J. L., Wang, X., and Zhu, T. 2002. Expression profile matrix of Arabidopsis transcription factor genes suggests their putative functions in response to environmental stresses. Plant Cell 14:559-574.

Chomczynski, P., and Sacchi, N. 1987. Single-step method of RNA isolation by acid guanidium thiocyanate-phenol-chloroform extraction. Anal. Biochem. 162:156-159.

Dardick, C. D., Golem, S., and Culver, J. N. 2000. Susceptibility and symptom development in Arabidopsis thaliana to Tobacco mosaic virus is influenced by virus cell-to-cell movement. Mol. Plant-Microbe. Interact. 13:1139-1144.

Deom, C. M., Oliver, M. J., and Beachy, R. N. 1987. The 30-kilodalton gene product of Tobacco mosaic virus potentiates virus movement. Science 237:389-394.

Escaler, M., Aranda, M. A., Thomas, C. L., and Maule, A. J. 2000. Peaembryonic tissues show common responses to the replication of a wide range of viruses. Virology 267:318-325.

Fraser, R. S. S., and Gerwitz, A. 1980. Tobacco mosaic virus infection does not alter the polyadenylated messenger RNA content of tobacco leaves. J. Gen. Virol. 46:139-148.

Gill, R. T., Katsoulakis, E., Schmitt, W., Taroncher-Oldenburg, G., Misra, J., and Stephanopoulos, G. 2002a. Genome-wide dynamic transcriptional profiling of the light-to-dark transition in Synechocystis sp. strain PCC 6803. J. Bacteriology 184:3671-3681.

Gill, R. T., Wildt, S., Yang, Y. T., Ziesman, S., and Stephanopoulos, G. 2002b. Genome-wide screening for trait conferring genes using DNA microarrays. Proc. Natl. Acad. Sci. U.S.A. 99:7033-7038.

Goelet, P., Lomonossoff, G. P., Butler, P. J. G., Akam, M. E., Gait, M. J., and Karn, J. 1982. Nucleotide sequence of Tobacco mosaic virus RNA. Proc. Natl. Acad. Sci. U.S.A. 79:5818-5822.

Havelda, Z., and Maule, A. J. 2000. Complex spatial responses to cucumber mosaic virus infection in susceptible Cucurbita pepo cotyledons. Plant Cell 12:1975-1985.

Hunter, T., Hunt, T., Knowland, J., and Zimmern, D. 1976. Messenger RNA for the coat protein of Tobacco mosaic virus. Nature London 260:759-764

Ishikawa, M., Meshi, T., Motoyoshi, F., Takamatsu, N., and Okada, Y. 1986. In vitro mutagenesis of the putative replicase genes of Tobacco mosaic virus. Nucleic Acids Res. 14:8291-8305.

Itaya, A., Matsuda, Y., Gonzales, R. A., Nelson, R. S., and Ding, B. 2002. Potato spindle tuber viroid strains of different pathogenicity induces and suppresses expression of common and unique genes in infected tomato. Mol. Plant-Microbe Interact. 15:990-999.

Matthews, R. E. F. 1991. Plant Virology, 3rd Edition. Academic Press, New York.

Meshi, T., Watanabe, Y., Saito, T., Sugimoto, A., Maeda, T., and Okada, Y. 1987. Function of the 30-kDa protein of Tobacco mosaic virus: Involvement in cell-to-cell movement and dispensability for replication. EMBO (Eur. Mol. Biol. Organ.) J. 6:2557-2563.

Newman, T., deBruijin, P., Green, P., Keegstra, K., Kende, H., McIntosh, L., Ohlrogge, J., Raikhel, N., Sommerville, S., Thomashow, M., Retzel, E., and Somerville, C. 1994. Genes galore: A summary of methods for accessing results from large-scale partial sequencing of anonymous Arabidopsis cDNA clones. Plant Physiol. 106:1241-1255.

Pelham, H. R. B. 1978. Leaky UAG termination codon in Tobacco mosaic virus RNA. Nature 272:469-471.

Samuel, G. 1934. The movement of Tobacco mosaic virus within the plant. Ann. Appl. Biol. 21:90-111.

Schaffer, R., Landgraf, J., Accerbi, M., Simon, V., Larson, M., and Wisman, E. 2001. Microarray analysis of diurnal and circadian-regulated genes in Arabidposis. Plant Cell 13:113-123.

Schuchhardt J., Beule, D., Malik, A., Wolski, E., Eickhoff, H., Lehrach, 
H., and Herzel, H. 2000. Normalization strategies for cDNA microarrays. Nucleic Acids Res. 28:E47.

Sherlock, G. 2000. Analysis of large-scale gene expression data. Curr Opin. Immunol. 12:201-205.

Sherlock, G., Hernandez-Boussard, T., Kasarskis, A., Binkley, G., Matese, J. C., Dwight, S. S., Kaloper, M., Weng, S., Jin, H., Ball, C. A., Eisen, M. B., Spellman, P. T., Brown, P. O., Botstein, D., and Cherry, J. M. 2001. The Stanford microarray database. Nucleic Acids Res. 29:152-155.

Thimm, O., Essigmann, B., Kloska, S., Altmann, T., and Buckhout, T. J. 2001. Response of Arabidopsis to iron deficiency stress as revealed by microarray analysis. Plant Physiol. 127:1030-1043.

Wang, D., and Maule, A. J. 1995. Inhibition of host gene expression associated with plant virus replication. Science 267:229-231.

Whitham, S. A., Quan, S., Chang, H.-S., Cooper, B., Estes, B., Zhu, T., Wang, X., and Hou, Y. M. 2003. Diverse RNA viruses elicit the expression of common sets of genes in susceptible Arabidopsis thaliana plants. Plant J. 33:271-283.

Yalamanchili P., Harris K., Wimmer E., and Dasgupta A. 1996. Inhibition of basal transcription by poliovirus: A virus-encoded protease (3Cpro) inhibits formation of TBP-TATA box complex in vitro. J. Virol 70:2922-2929.

\section{AUTHOR-RECOMMENDED INTERNET RESOURCES}

Munich Information Center for Protein Sequences (MIPS) A. thaliana website: www.mips.biochem.mpg.de/proj/thal/db/about/matdbintro.html

M. Eisen's Public Library of Science project Scanalyze software webpage: rana.lbl.gov/EisenSoftware.htm

Stanford University's Arabidopsis Functional Genomics Consortium (AFGC): afgc.stanford.edu

The Stanford University microarray database: genome-www5.stanford. edu/ MicroArray/SMD 